\title{
Occurrence of purslane leaf spot caused by Dichotomophthora lutea in Iran
}

\author{
Kobra Heidari $^{1} \cdot$ Reza Farokhinejad ${ }^{1} \cdot$ Mehdi Mehrabi-Koushki $^{1,2}$ (D) \\ Received: 16 June 2018 / Accepted: 14 September 2018 / Published online: 17 September 2018 \\ (C) Australasian Plant Pathology Society Inc. 2018
}

\begin{abstract}
Since 2015, a leaf disease showing necrotic, oval to irregular, pale brown spots with darker border had been observed on purslane in Khuzestan province, Iran. Symptomatic plants were collected and conducted to laboratory where five isolates were obtained. Based on a phylogenetic analyses using ITS and rpb2 regions, in combination with morphological characterization, the pathogen was identified as Dichotomophthora lutea. Pathogenicity of this fungus was confirmed by the inoculation of health leaves of purslane. To our knowledge, this is the first report of this pathogen on purslane in Iran.
\end{abstract}

Keywords Conidia $\cdot$ Conidiophores $\cdot$ Disease $\cdot$ Portulaca oleracea

Purslane (Portulaca oleracea) is one of the most important cultivated vegetable crops in the southern regions of Iran, such as Khuzestan province. This plant is affected by a variety of infectious diseases in Iran, which cause great loss in crop yield and quality, i.e. white rust (Albugo portulacae), club root (Olpidium brassicae) and root rot (Rhizoctonia solani) (Ershad 2009). Since 2015, leaf spot disease had been observed in purslane fields of Khuzestan province. The disease is characterized by necrotic, oval to irregular, pale brown spots, with darker borders (Fig. 1).

In order to identify the causal agent, five symptomatic plants were collected from purslane fields of Abadan and Ahvaz cities in Khuzestan province during 2017. Small pieces were excised from the interface between healthy and diseased leaf tissue and surface-sterilised by $2 \%$ sodium hypochlorite ( $2 \mathrm{~min}$ ), followed by washing with sterile distilled water. The pieces were plated in dishes containing potato dextrose agar (PDA, Merck), supplemented with streptomycin $(30 \mathrm{mg} / \mathrm{L})$. After incubating at $28{ }^{\circ} \mathrm{C}$ for five days, grown colonies were transferred to fresh PDA and purified by the single-spore method. Five isolates of a phragmoconidia-producing fungus were obtained; all of them

Mehdi Mehrabi-Koushki

mhdmhrb@scu.ac.ir; mhdmhrb@gmail.com

1 Plant Protection Department, Agriculture Faculty, Shahid Chamran University of Ahvaz, Khuzestan Province, Ahvaz, Iran

2 Biotechnology and Bioscience Research Center, Shahid Chamran University of Ahvaz, Khuzestan Province, Ahvaz, Iran appeared to be morphologically identical based on a preliminary analysis. Isolates SCUA-C, from Abadan, and SCUA-17, from Ahvaz, were selected for further characterization. These isolates were deposited in the Centraalbureau voor Schimmelcultures, Utrecht, The Netherlands (CBS 144679= SCUA-C and CBS $144680=$ SCUA-17).

The isolates were grown on PDA at $28^{\circ} \mathrm{C}$, at $12 \mathrm{~h}$ fluorescent light and $12 \mathrm{~h}$ darkness. The slide cultures were prepared as described by Beneke and Rogers (1996). Micromorphological characters (e.g. conidiophores and conidia) of the isolates were studied at 10 days post-inoculation using the microscopic slides. At least 50 measurements for each fungal structure were carried out with $40 \times$ and $100 \times$ objective lens of a Leitz wetzlar (SM-LUX) Basic Biological Light Microscope. Photomicrographs were obtained using an OLYMPUS BX51 microscope fitted with an OLYMPUS DP12 digital camera.

For molecular studies, mycelial biomass was produced in potato dextrose broth (PDB) at $100 \mathrm{rpm}$ in dark at $28^{\circ} \mathrm{C}$ for 10 days. The mycelia were collected by passing through sterile filter papers and freeze-dried (Freeze Dryer, Alpha 1-2 LDplus, Christ), followed by powdering in mortar containing liquid nitrogen. Genomic DNA was extracted from powdered mycelia according to the protocol of Raeder and Broda (1985), with some optimization in the procedure (Ahmadpour et al. 2017). Partial region of nuclear ribosomal RNA (including internal transcribed spacer 1 and 2 and 5.8S nrDNA) and RNA polymerase II (rpb2) were amplified using the primer pairs ITS1/ITS4 (White et al. 1990) and RPB25F2/fRPB2-7cR (Sung et al. 2007; Liu et al. 1999), 
Fig. 1 Natural and artificial disease symptoms on Portulaca oleracea leaves caused by Dichotomophthora lutea CBS 144679. a, symptoms on leaves collected from purslane fields of Abadan in Khuzestan province, Iran. $\mathbf{b}$, trial pot used in pathogenicity test. c, leaf spot caused by placing a $0.1 \mathrm{ml}$ drop of spore suspension on the leaf. $\mathbf{d}$, leaf spot caused by injecting $0.1 \mathrm{ml}$ spore suspension into the leaf
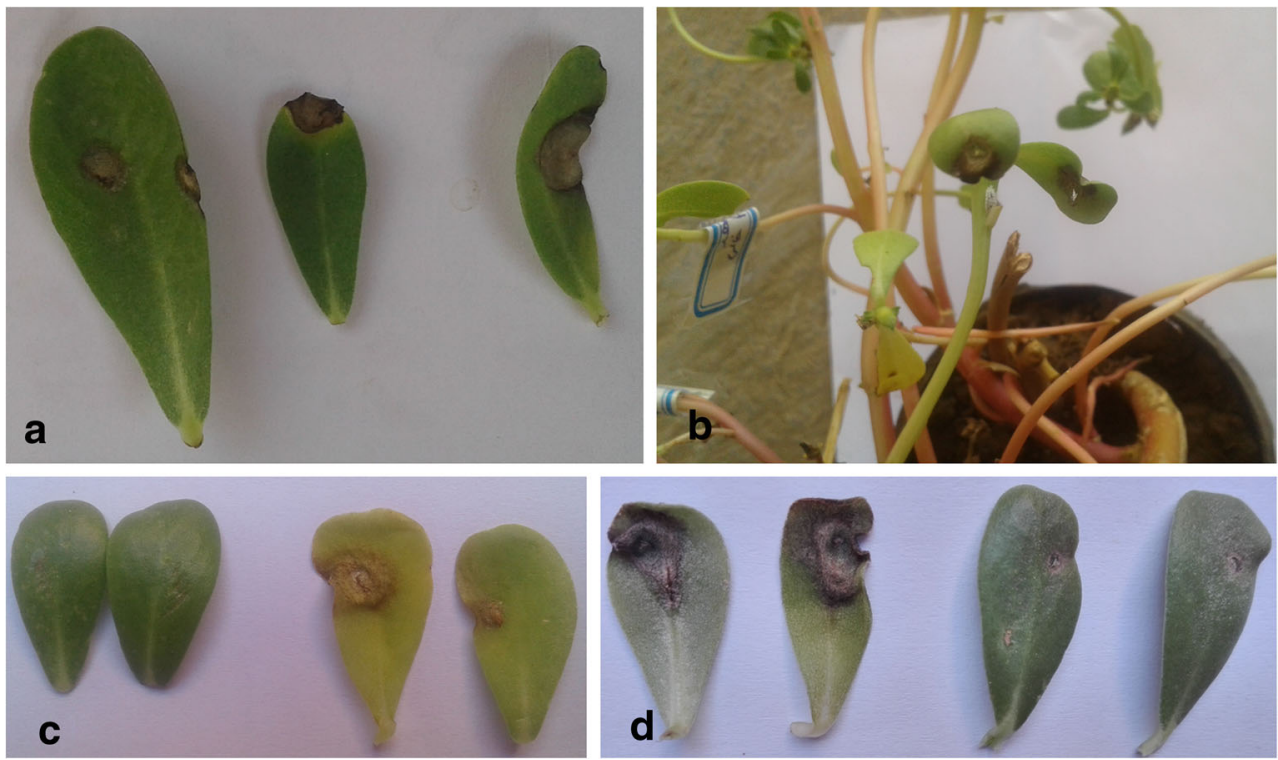

respectively. The PCR products of the expected size, appeared in gel electrophoresis, were excised and purified by the GF-1 AmbiClean Kit (Vivantis, Malaysia), according to the manufacturer's instructions. The amplicons were sequenced (Humanizing Genomics, Macrogen, South Korea) and compared to indexed sequences in GenBank by BLAST algorithm and phylogenetic analysis. A phylogenetic analysis based on the combined sequences of the ITS and $\mathrm{rpb} 2$ regions was performed using the maximum likelihood (ML) algorithm in the MEGA6 software (Tamura et al. 2013). Accession numbers of the sequences retrieved from GenBank and used in the phylogenetic analysis of the present study are available in Marin-Felix et al. (2019).

Pathogenicity of isolates CBS 144679 and CBS 144680 was tested on two-month purslane plants (variety of Ahvaz) growing in the trial pots (Fig. 1). Spore suspension was harvested from the agar surface of 15 -days cultures by flooding with $0.1 \%$ Tween- 20 solution and cleaned by passing through glass wool. Spore suspension were washed two-times using sterile distilled water and centrifugation at $3000 \mathrm{xg}$. The spore concentration was adjusted to $10^{7}$ per $\mathrm{ml}$ using a haemocytometer slide. Foliar inoculation was performed in two ways: placing a $0.1 \mathrm{ml}$ drop of spore suspension on the leaves or injecting it into the leaves using a hypodermic syringe. Sterile water was used as the control. Eight leaves were inoculated for each method and incubated at $28^{\circ} \mathrm{C}$. The pots were covered with plastic bags for the first 48 -h and then pots were uncovered.

The partial nrDNA and rpb2 sequences of Dichotomophthora lutea CBS 144679 and CBS 144680 were deposited in GenBank (Accession Nos. MG846730, MH427866, MH458444 and MH500843). Using a BLAST algorithm, the ITS and rpb2 sequences of both isolates showed $100 \%$ identity to reference strains of the species $D$. lutea (CBS
585.71 and CBS 132.81). The combined tree of ITS and $\mathrm{rpb} 2$ regions showed that both isolates under study clustered with the reference strains of $D$. lutea and formed a monophyletic clade with strong support (Fig. 2).

The accurate morphology and morphometry of both isolates appeared to be either almost identical, and $D$. lutea isolates obtained in the present study (Fig. 3) showed irregular colonies with undulate margin, pigmented, greyish white with blackish grey edge, aerial mycelium abundant, cottony; reverse dark brown to black, paler towards the edge of the colony, with age becoming darker. Hyphae hyaline to pale brown, branched, septate, 4.3-8.6(-10.8) $\mu \mathrm{m}$ diam. Conidiophores arising singly, septate, straight, cell walls thicker than those of vegetative hyphae, pale brown, branched in apical region, mostly bifurcated, generally equal wide in main branch, penultimate branches narrower, apical branches end in one or more conidiogenous heads, heads with 2 or more apical rounded spore bearing lobes, size in main branch $(137.8-) 208-884(-1092) \times 9.72-16.2 \mu \mathrm{m}, 95 \%$ confidence

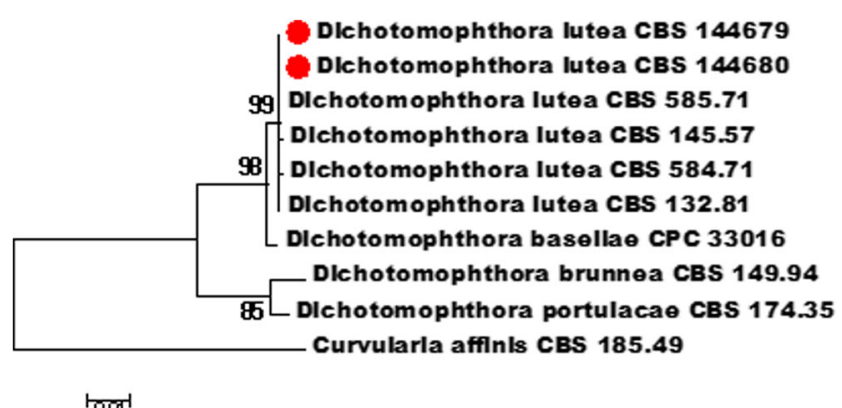

'00'

Fig. 2 Phylogenetic tree constructed from a maximum likelihood analysis based on a concatenated alignment of ITS and rpb2 sequences of two Dichotomophthora lutea isolates surveyed and seven reference strains representing the valid species of Dichotomophthora. The tree was rooted with Curvularia affinis CBS 185.49 
Fig. 3 Dichotomophthora lutea CBS 144679. a-b, colony on PDA (front and reverse). c-e, hyphae, conidiophores, heads and lobes. $\mathbf{f}-\mathbf{g}$, conidia
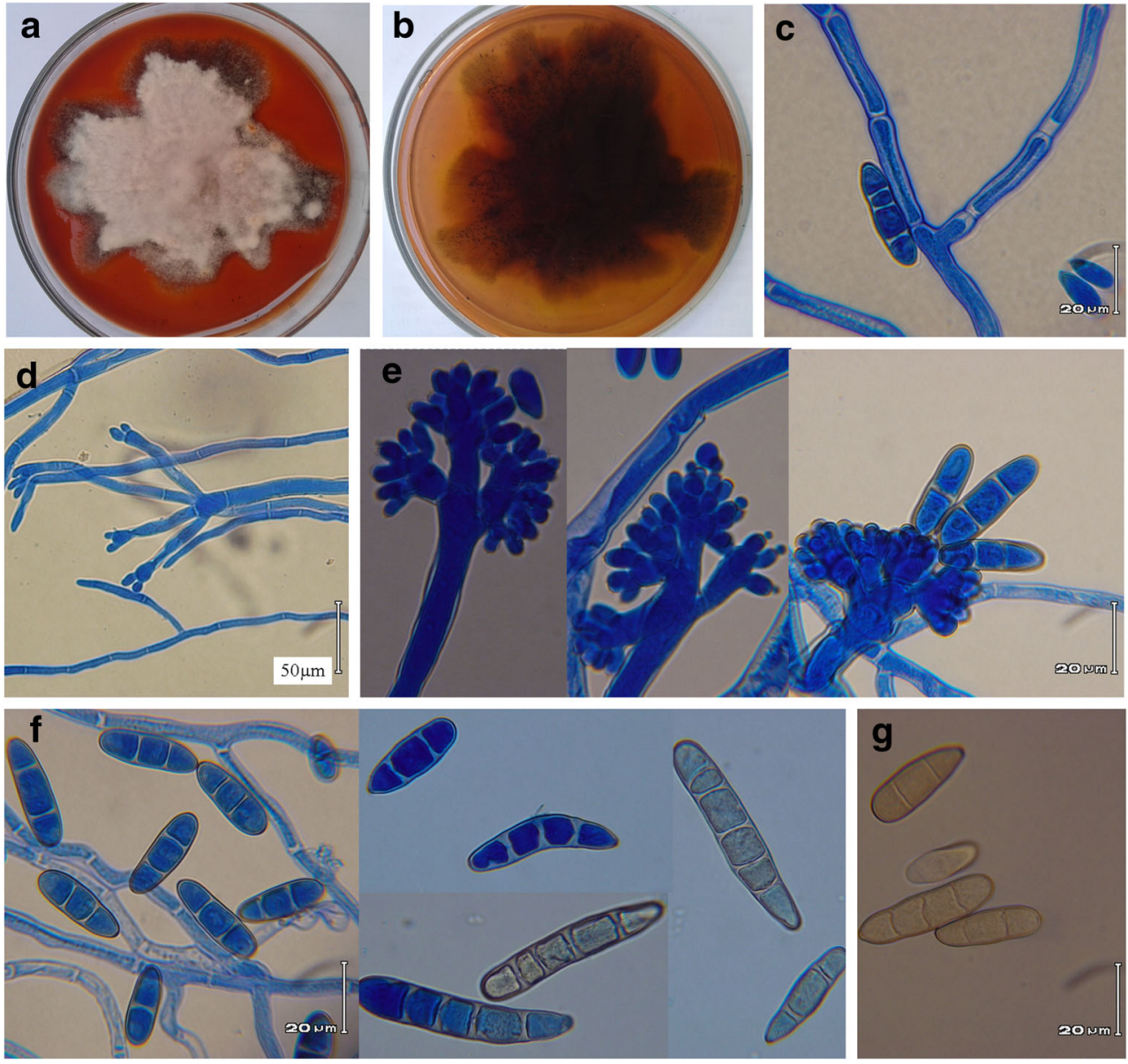

limits $=456.4-566.2 \times 12-12.9 \mu \mathrm{m},\left(\mathrm{x}^{-} \pm \mathrm{SD}=511.3 \pm\right.$ $221.4 \times 12.4 \pm 1.6 \mu \mathrm{m}, n=50)$. Conidia produced singly on the lobes, smooth- and thick walled, straight, rarely veryslightly curved, ellipsoidal to cylindrical, approximately narrowed in basal end and rounded in apex, pale brown, 14(5)-distoseptate, 11.9-49.7(-60.5) ×6.5-14.4 $\mu \mathrm{m}, 95 \%$ confidence limits $=28.7-35.3 \times 10.1-11.2 \mu \mathrm{m},\left(\mathrm{x}^{-} \pm \mathrm{SD}=32 \pm\right.$ $12.5 \times 10.6 \pm 2 \mu \mathrm{m}, n=70)$. Chlamydospore, sclerotia and sexual morph not observed.

Dichotomophthora is a monophyletic genus with four valid species to date (de Hoog and van Oorschot 1983; Marin-Felix et al. 2019), including D. basellae, D. brunnea, D. lutea and $D$. portulacae. The D. lutea isolates investigated in the present study showed somewhat shorter and narrower conidia than those described for the ex-type strain, D. lutea CBS 145.57 (11.9-49.7 × 6.5-14.4 $\mu \mathrm{m}$ vs. $30-115 \times 10-20 \mu \mathrm{m}$ in size) (de Hoog and van Oorschot 1983). However, as mentioned above general morphology and phylogenetic analysis proved that both isolates fit well with $D$. lutea species.

Both isolates were able to caused necrotic lesions three days after inoculation. No symptoms were observed in the control plants (Fig. 1). Disease appeared as oval to irregular, grey to greyish-brown lesions without any distinct border on the leaves. These spots developed an anthracnose-like sunken center as the lesions enlarged. Over time, the symptomatic leaves turned yellow and dropped. Both isolates under study were re-isolated and re-identified as described above, fulfilling Koch's postulates.

Most known strains of the Dichotomophthora genus were isolated from the leaves, stems, seeds and roots of the herbaceous and wooden plants, including Anredera spp., Basella spp., Beta vulgaris, Gymnocalycium mihanovichii var. friedrichii, Myrtillocactus geometrizans and Portulaca spp. (Mehrlich and Fitzpatrick 1935; Rao 1966; Barron 1968; Ellis 1971; Klisiewicz et al. 1983, Baudoin 1986; Mitchell 1986; Eken 2003; Jing et al. 2008; Soares and Nechet 2017). These strains have been commonly reported as plant pathogen causing damping-off, foliar abscission, leaf spots, root rot, seed rot and stem blight; some of them are also saprophyte in soil (Marin-Felix et al. 2019). In literature review, D. lutea was reported to be isolated from Portulaca oleracea in India, The Netherlands and Cuba and seedbed of Pinus radiata in Italy (de Hoog and van Oorschot 1983). In addition, this species (Synonym: $D$. indica) was known as stem blight pathogen of $P$. oleracea in the USA (Baudoin 1986) and the causal agent of weed leaf spot in India (Rao 1966) and Canada (Barron 1968). Portulaca oleracea is also known to be infected by D. portulacae (Mehrlich and Fitzpatrick 1935; Ellis 
1971; Klisiewicz et al. 1983; Mitchell 1986; Eken 2003; Jing et al. 2008). Additionally, two other Dichotomophthora species were recently described on distinct hosts (Marin-Felix et al. 2019), plus an unkown Dichotomophthora species on Anredera cordifolia (Soares and Nechet 2017). All these species share some morphological similarities and the distinction between them can be puzzling without the use of molecular tools (Marin-Felix et al. 2019).

To our knowledge, this is the first record of both, the genus Dichotomophthora and the species D. lutea in Iran. This study will improve the integrated diseases management of vegetables in Iran.

Acknowledgements This work was financially supported by grants from the Research Council of Shahid Chamran University of Ahvaz.

\section{References}

Ahmadpour SA, Mehrabi-Koushki M, Farokhinejad R (2017) Neodidymelliopsis farokhinejadii, a new fungal species from dead branches of trees in Iran. Sydowia 69:171-182

Barron GL (1968) The genera of Hyphomycetes from soil. Williams \& Wilkins Company, Baltimore, p 364

Baudoin ABAM (1986) First report of Dichotomophthora indica on common purslane in Virginia. Plant Dis 70:352

Beneke ES, Rogers AL (1996) Medical mycology and human mycoses. Star Publishing Company, Belmont, 239 pp

de Hoog GS, van Oorschot CAN (1983) Taxonomy of the Dactylaria complex. I. Notes on the genus Dichotomophthora. Proc Kon Ned Akad Wetensch Sect C 86:55-61

Eken C (2003) Dichotomophthora portulacae on Portulaca oleracea in Turkey. Mycotaxon 87:153-156

Ellis MB (1971) Dematiaceous Hyphomycetes. Common wealth mycological institute, Kew, Surrey, England. 608 pp
Ershad D (2009) Fungi of Iran, 3rd edn. Iranian Research Institute of Plant Protection, Tehran

Jing J, Diao L-G, Lu B-S, Li B-D (2008) The finding of Dichotomophthora portulacae in China. Mycosystema 27:601-603

Klisiewicz JM, Clement SL, Norris RF (1983) Black stem: a fungal disease of common after inoculation. Four weeks after purslane in California. Plant Dis 67:1162

Liu YJ, Whelen S, Hall BD (1999) Phylogenetic relationships among ascomycetes: evidence from an RNA polymerse II subunit. Mol Biol Evol 16(12):1799-1808

Marin-Felix Y, Hern_andez-Restrepo M, Wingfield MJ, Akulov A et al (2019) Genera of phytopathogenic fungi: GOPHY 2. Stud Mycol 92:47-133

Mehrlich FP, Fitzpatrick HM (1935) Dichotomophthora portulacae, a pathogene of Portulaca oleracea. Mycologia 27:543-550

Mitchell JK (1986) Dithotomophthora portulacae causing black stem rot on common purslane in Texas. Plant Dis 70:603

Raeder U, Broda P (1985) Rapid preparation of DNA from filamentous fungi. Lett Appl Microbiol 1:17-20

Rao PN (1966) A new species of Dichotomophthora on Portulaca oleracea from Hyderabad-India. Mycopathol Mycol Appl 28:137140

Soares DJ, Nechet KL (2017) Dichotomophthora sp. causing leaf spot and foliar abscission on Anredera cordifolia in Brazil. Austr Plant Dis Notes 12:51

Sung G-H, Sung J-M, Hywel-Jones NL, Spatafora JW (2007) A multigene phylogeny of Clavicipitaceae (Ascomycota, Fungi): identification of localized incongruence using a combinational bootstrap approach. Mol Phylogenet Evol 44(3):1204-1223

Tamura K, Stecher G, Peterson D, Filipski A, Kumar S (2013) MEGA6: molecular evolutionary genetics analysis version 6.0. Mol Biol Evol 30:2725-2729

White TJ, Bruns T, Lee S, Taylor J (1990) Amplification and direct sequencing of fungal ribosomal RNA genes for phylogenetics. In: Innis MA, Gelfand DH, Sninsky JJ, White TJ (eds) PCR protocols: a guide to methods and applications. Academic Press, New York, pp 315-322 